\title{
Development of an electrochemical biosensor for Galectin-3 detection in point-of-care
}

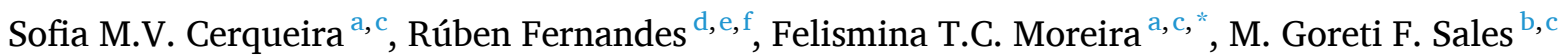 \\ ${ }^{\text {a }}$ BioMark Sensor Research - ISEP, School of Engineering, Polytechnic Institute of Porto, Portugal \\ ${ }^{\mathrm{b}}$ BioMark, Sensor Research/UC, Department of Chemical Engineering, Faculty of Science and Technology, Coimbra University, Coimbra, Portugal \\ ${ }^{\mathrm{c}}$ CEB, Centre of Biological Engineering, Minho University, Portugal \\ ${ }^{\mathrm{d}}$ Labmi - PORTIC - Porto Research, Technology \& Innovation Center, Polytechnic Institute of Porto, Portugal \\ ${ }^{\mathrm{e}}$ Escola Superior de Saúde, Polytechnic Institute of Porto, Portugal \\ f $i 3 S$ - Institute of Health and Research Innovation, University of Porto, Portugal
}

\section{A R T I C L E I N F O}

\section{Keywords:}

Melanoma

Screen-printed-electrode

Molecularly-imprinted polymer

Biosensor

Galectin-3

\begin{abstract}
A B S T R A C T
This research work aims the development and optimization of an electrochemical biosensor based on molecularly-imprinted polymers [MIPs], for monitoring a melanoma biomarker, Galectin-3 (Gal-3). As it is a multifunctional protein that plays an important role in different types of tumors including melanoma, and has shown good results as a potential biomarker in several areas, the construction of a biosensor for the detection of this protein would be a simple and quick strategy to support the treatment of this type of pathology.

The target molecule was recognized by a MIP material, created on the electrode's surface by electropolymerizing a mixture of analyte (Gal-3) and monomer (2-aminophenol). Then, the protein was removed from the polymeric material by oxalic acid treatment.

This process formed a non-conductive polymer with recognition sites showing affinity for the Gal-3. The control of the surface modification was monitored by Raman spectroscopy and electroanalytical techniques, namely electrochemical impedance spectroscopy (EIS) and cyclic voltammetry (CV). The analytical performance of the sensor was evaluated by EIS, by following the analytical response of standard solutions ranging from 0.5 $\mathrm{ng} / \mathrm{mL}$ to $5000 \mathrm{ng} / \mathrm{mL}$ Gal-3 in spyked serum. In general, the biosensor displayed good analytical features, considering limit of detection, response time and reproducibility.

Overall, this study resulted from the need to create a new strategy for monitoring melanoma through the creation of a cheaper, faster and sensitive device, which can be commercialized and thus integrate the entire process associated with the treatment and follow-up of this pathology.
\end{abstract}

\section{Introduction}

Melanoma is a malignant neoplasm that has origin in melanocytes and develops when irreparable damage occurs in the DNA of skin cells $[1,2]$. This type of tumors results from the malignant transformation of melanocytes (melanin producers in the basal layer of the epidermis) that has origin in the neural crest and migrate to the skin and other sites on the periphery, during fetal development $[3,4]$.

The incidence of skin cancer in Portugal remains a concern, when compared to the European average. In the specific case of melanoma, it represents only $4 \%$ of skin cancers, but it is also the most aggressive form of the disease, due to its high metastatic potential, being responsible for about $75 \%$ of deaths that are associated with skin cancer [5].
Although there are clinical, biochemical and histological methods that provide information about the behavior of this pathology, it remains an unpredictable disease. As it has a high mortality rate, there is a need to look for new biomarkers that are suitable and useful for early diagnosis, staging, prognosis, as well as monitoring response to treatment. Biomarkers have molecular properties with potential use in disease detection and diagnosis, while also providing information related to the biological behavior of the tumor, and the mechanisms that are associated with resistance and/or sensitivity to treatment [6]. Currently, there is no ideal biomarker in melanoma, and pathological features of the tumor such as Breslow thickness, mitotic rate and ulceration status are important prognostic factors, which can only be determined after completion of a biopsy or surgical resection of the tumor [7-9]. This is

\footnotetext{
* Corresponding author at: BioMark/Instituto Superior de Engenharia do Porto, R. Dr. António Bernardino de Almeida, 431, 4200-072 Porto, Portugal.

E-mail address: ftm@isep.ipp.pt (F.T.C. Moreira).
} 
an invasive process, which would be avoided if circulating biomarkers existed. The melanoma cells and the associated extracellular molecules may provide non-invasive analytical access, for releasing proteins and other cells in the extracellular fluid that may reach the bloodstream, which can serve as serum biomarkers [10-12].

Studies carried out in the area have shown that in certain types of cancer, such as breast, thyroid, colorectal and melanoma cancer, there is a dysregulation of galactins, which cause an inhibition of tumor cell apoptosis, promoting tumor growth and increasing the development of metastases [13-16]. Regarding specifically Galectin-3 (Gal-3), it is a multifunctional protein that is a member of the lectin family, with a chimeric structure that plays an important role in adhesion, proliferation, differentiation, angiogenesis and metastasis in various tumor types. Its expression is positively correlated with the metastatic potential of human melanoma cell lines $[13,17]$.

According to the literature, some studies indicated that increased Gal-3 levels in the serum of some patients with melanoma cancer might reflect biological aspects of tumor behavior related with a metastasizing phenotype. Other studies have demonstrated the clinical value of circulating Gal-3 in patients with early-stage cancer, signalling it as a predictor of tumor invasion and metastasis.

Low serum levels of Gal-3 were detected in healthy individuals (median, $62 \mathrm{ng} / \mathrm{ml}$; range, $20-313 \mathrm{ng} / \mathrm{ml}$ ). Compared with healthy people, Gal-3 serum levels in patients with breast, gastrointestinal, lung, or ovarian cancer, melanoma, and non-Hodgkin's lymphoma were expressively elevated. Maximum serum concentrations of Gal-3 (median, $320 \mathrm{ng} / \mathrm{ml}$; range, $20-950 \mathrm{ng} / \mathrm{ml}$ ) were obtained in patients with metastatic gastrointestinal carcinoma. Overall, these results propose that circulating Gal-3 could be a promising biomarker [18].

Interestingly, available evidence indicates that Gal-3 is also vital for normal brain development and plays various roles in central nervous system (CNS) inflammation, with re-modeling capacity in damaged CNS tissues [19]. Gal-3 plays also an important role in the pathogenesis of neuroinflammatory and neurodegenerative disorders, such as multiple sclerosis, Alzheimer's disease, Parkinson's disease, and Huntington's disease [20].

Regarding the protein detection, there are several methods that can be used in the field of electrochemistry [21-24], such as optical [25,26], and separative methods [27], among others. Considering that Gal-3 is a relevant potential biomarker in several areas of health, it would be also important to have a biosesnor for this biomarker too. Since electrochemical biosensors are sensitive, selective, accessible and relatively easy in terms of development, when compared to other techniques that could be used, it was found that the construction of a biosensor for the detection of this protein would be the quickest and simplest way to develop a new strategy to support the treatment of melanoma, by monitoring the effectiveness of radiotherapy $[28,29]$.

A biosensor is, in general, an autonomous device capable of providing quantitative or semi-quantitative analytical information using a biological recognition element (biochemical receptor), which is in direct contact with a transducer element. In this way, it measures biological or chemical reactions, generating signals that are proportional to the concentration of the analyte in the reaction. It is an analytical device that converts a biological response into a processable and quantifiable signal. Regarding its constitution, a biosensor consists of an analyte (represents the substance of interest), a biorecognition element (molecule that specifically recognizes the target analyte), a transducer (it is an element that converts one form of energy into another), an electronic system (responsible for processing the transduced signal and preparing it for the display) and the display (user interpretation system).

Regarding the elements of biorecognition, this set includes antibodies [30,31], enzymes [32,33] plastic antibodies (molecular printing polymers) [34-38], DNA /RNA [39-41] and aptamers [42-47]. Only the use of antibodies as a biorecognition element in biosensors was found in the literature for the detection of Gal-3, however none was found for the detection of this protein in melanoma $[48,49]$.
The development of biosensors that use MIPs as an element of biorecognition for the detection of Gal-3, they do not yet exist in the literature. However, it is hoped that this work will serve as a starting point for the study and development of new biosensors, especially focusing the area of melanoma and with MIP materials. The creation of artificial macromolecular receptors with high affinity and selectivity, capable of recognizing and binding to a particular molecular target, using a molecular printing compared to natural systems, is a low-cost, simple and robust method, with high-recognition, long-term durability and fully compatible with sensor surface, which allows MIPs to be used in several areas. Molecular imprinting is a technology that allows the production of polymers with specific recognition sites, moulded from a mould molecule, which can be the analyte itself or a compound with a similar structure $[36,50]$. Several electrochemical biosensors based on MIPs as a biorecognition element have been reported in the literature for diverse target molecules as proteins, toxins, and antibiotics, among of others [51-55].

MIP-based sensors can be obtained chemically (by treatment with an external reactant) or electrochemically (by electropolymerization). Chemical synthesis of MIPs mostly includes monomers, which polymerize after addition of an initiator. Chemical synthesis is frequently used for preparation of polymers in solutions or in bulk solids [56]. In contrast, electropolymerization is mainly used for deposition of MIPs in a conductive support material. The main advantages of this strategy is the prospect to control (1) the rate of polymer growth, by appropriate selection of the electropolymerization parameters, (2) the film thickness, by the controlling the current passed through film deposition, and (3) the film morphology, by proper selection of an suitable solvent and supporting electrolyte. Due the inherent advantages of this approach, several molecularly-imprinted proteins have been reported in the literature for point-of-care (PoC) applications [57-59].

In this way, MIPs present microcavities that are complementary to the mold in shape, size and chemical functionality, and can selectively retain the mold molecule present in a sample, as Gal-3, eliminating possible interferents that are present. MIPs combined with electrochemical sensing may lead to a new strategy for monitoring melanoma by means of the creation of a cheaper, faster and sensitive device sensitive to Gal-3, which can be later on contribute to the treatment and follow-up of this pathology.

\section{Experimental section}

\subsection{Apparatus}

The eletrochemical measurements were performed using a Metrohm Autolab potentiostat/galvanostat controlled by Nova 1.11 software and the C-SPE used were purchased from DROPSENS (DRP-C220AT) and composed by a ceramic substrate with electrical contacts made of silver, with a working electrode ( $4 \mathrm{~mm}$ in diameter) and an auxiliary electrode both made of carbon and a silver reference electrode. These are placed in a suibtable conector box that interfaces the C-SPE with the potentiostat/ galvanostat.

In addition, the material structure and surface analysis of the C-SPE was performed using Raman Spectroscopy and for this purpose, a confocal microscopy Thermo Scientific DXR Raman spectrometer equipped with a $532 \mathrm{~nm}$ excitation laser was used.

\subsection{Reagents}

The electrochemical assays were performed using potassium hexacyanoferrate III $\left(\mathrm{K}_{3}\left[\mathrm{Fe}(\mathrm{CN})_{6}\right]\right)$ and potassium hexacyanoferrate II trihydrate $\left(\mathrm{K}_{4}\left[\mathrm{Fe}(\mathrm{CN})_{6}\right] \cdot 3 \mathrm{H}_{2} \mathrm{O}\right)$ from Riedel-de-Haen; potassium chloride $(\mathrm{KCl})$ and oxalic acid dehydrate from Merck; phosphate buffered saline (PBS) and bovine serum albumin (BSA) from Amresco; sulphuric acid 95-97\% $\left(\mathrm{H}_{2} \mathrm{SO}_{4}\right)$ and CA15-3 from Sigma Aldrich; 3-Aminophenol 99\% from Acros Organics, CORMAY serum HN from Cormay ${ }^{\circledR}$; recombinant 
human Galectin-3 protein from Alfa Aesar; and creatinine from Fluka.

\subsection{Solutions}

The electrochemical assays were performed using a $5.0 \times 10^{-3} \mathrm{M}$ $\mathrm{K}_{4}\left[\mathrm{Fe}(\mathrm{CN})_{6}\right]$ and $5.0 \times 10^{-3} \mathrm{M} \mathrm{K}_{3}\left[\mathrm{Fe}(\mathrm{CN})_{6}\right]$, prepared in $\mathrm{KCl}$ electrolyte. The PBS solution was prepared in ultrapure water, with a $\mathrm{pH}$ of 7.4, and the $\mathrm{H}_{2} \mathrm{SO}_{4}$ solution was prepared with a $0.50 \mathrm{M}$ concentration, in ultrapure water. Aminophenol (99\%) and oxalic acid solutions were prepared in PBS and ultrapure water, respectively, with a concentration of $1.0 \times 10^{-3} \mathrm{M}$ of aminophenol and $0.50 \mathrm{M}$ of oxalic acid. The Gal-3 was diluted in $1.0 \mathrm{~mL}$ of PBS having a concentration of $50 \mu \mathrm{g} / \mathrm{mL}$. The stock solutions for the calibration curves were prepared in PBS buffer and the most diluted standards were obtained by rigorous dilution of the previous solution, in the same buffer.

The selectivity study was performed with possible interfering species such as glucose, creatinine, BSA and the tumor marker. All compounds were prepapred in PBS buffer. In the case of creatinine and BSA, it was necessary to dilute 100 and 1000 times respectively, to avoid possible disproportionate interference of the compounds.

\subsection{Electrochemical synthesis of molecular imprinted (MIP) and non- imprinted polymer (NIP) films}

The preparation and construction of the sensor was done in three steps: electrochemical cleaning, electropolymerization and protein removal, as illustrated in Fig. 1. To this end the C-SPE's were subjected, first, to an electrochemical pre-treatment by chronoamperometry $(1.7 \mathrm{~V}$, for $200 \mathrm{~s}$, in $\mathrm{KCl} 0.1 \mathrm{M}$ solution), in order to remove possible contaminants that may be present on the electrode surface. Then, in order to promote their activation through the appearance of functional groups by cyclic voltammetry (CV) ( -0.2 to $1.2 \mathrm{~V}, 15$ cycles, $0.05 \mathrm{~V} / \mathrm{s}$ in $\mathrm{H}_{2} \mathrm{SO}_{4} 0.5$ $\mathrm{M})$. After electrochemical cleaning, a solution consisting of aminophenol $\left(1.0 \times 10^{-3} \mathrm{M}\right)$ and Gal-3 $(5.0 \mu \mathrm{g} / \mathrm{mL})$ in PBS buffer was used to assemble the MIP layer by electropolymerization. In parallel, the nonmolecularly imprinted polymer (NIP) was prepared, in the same way as the MIP but without the presence of the protein. Then, $100 \mu \mathrm{l}$ of each solution was placed on the corresponding C-SPE and the

\section{C-SPE}

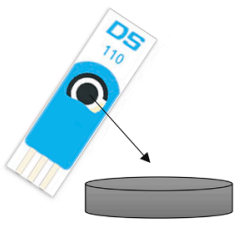

(A)

\section{IMPRINTING} STAGE

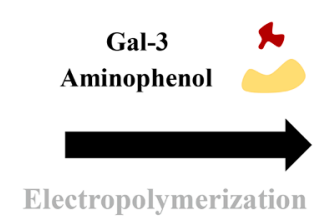

Electropolymerization

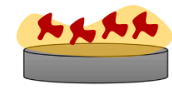

(B)

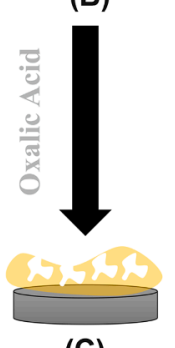

(C)

\section{TEMPLATE} REMOVAL
Fig. 1. Schematic representation of the synthetic process. (A) Working area of C-SPE; (B) Imprinting stage after electropolymerization of Galectin-3 with aminophenol (C) Binding site after template removal by oxalic acid. electropolymerization was carried out by CV ( -0.2 to $0.8 \mathrm{~V}, 10$ cycles, $0.05 \mathrm{~V})$. Subsequently, the polymeric film was washed with $\mathrm{KCl}$ and incubated with $5 \mu \mathrm{l}$ of oxalic acid ( $0.5 \mathrm{M}$ in deionized water), placed on the working electrode surface, at room temperature, overnight. Then, the sensing surface was washed with $\mathrm{KCl}$ and incubated in PBS buffer for $30 \mathrm{~min}$ for cleaning and $\mathrm{pH}$ stabilization. In this process, Gal-3 is extracted from the polymeric films by acidic action and the binding cavities are formed; these cavities are complimentary to the protein in size, shape and functionality.

\subsection{Electrochemical assays}

The electrochemical assays were indirectly measured using $5.0 \times$ $10^{-3} \mathrm{M} \mathrm{K}_{3}\left[\mathrm{Fe}(\mathrm{CN})_{6}\right]$ and $5.0 \times 10^{-3} \mathrm{M} \mathrm{K}_{4}\left[\mathrm{Fe}(\mathrm{CN})_{6}\right]$ prepared in $\mathrm{KCl}$ electrolyte as redox probe and the chronoamperometry, $\mathrm{CV}$, square wave voltammetry and electrochemical impedance spectroscopy techniques (EIS) were used to characterize the sensors in different steps of construction and optimization. The calibration curve was performed by EIS measurements, in order to check the response of Gal-3 solution prepared in PBS buffer in a range from $5.0 \mathrm{ng}$ to $50.0 \mu \mathrm{g} / \mathrm{mL}$. The sensors were incubated with $5 \mu \mathrm{l}$ of Gal-3-PBS solution, for $20 \mathrm{~min}$, at room temperature. Between each incubation, the sensor was washed with $\mathrm{KCl}$ and dried.

\section{Results and discussion}

\subsection{Electropolymerization and imprinting stage}

The molecular imprinting of Gal-3 was performed by electropolymerization of a solution containing 2-aminophenol and Gal-3 in PBS buffer. The correct selection of the monomer is critical once its functional groups will interact with specific protein sites, promoting greater effectiveness of the molecular impression. For electropolymerization, the monomer 2-aminophenol was chosen, because it has two different functional groups that can easily interact with the chemical functions existing on aminoacides at the outer surface of Gal-3. Electropolymerization was performed by consecutive $\mathrm{CV}$ cycles on the surface of C-SPE's (Fig. S1).

In the first cycle, the current increased towards the oxidation potentials, reaching a peak around $0.2 \mathrm{~V}$, which represented the oxidation of the monomer. After electropolymerization (Fig. 2) it was found that

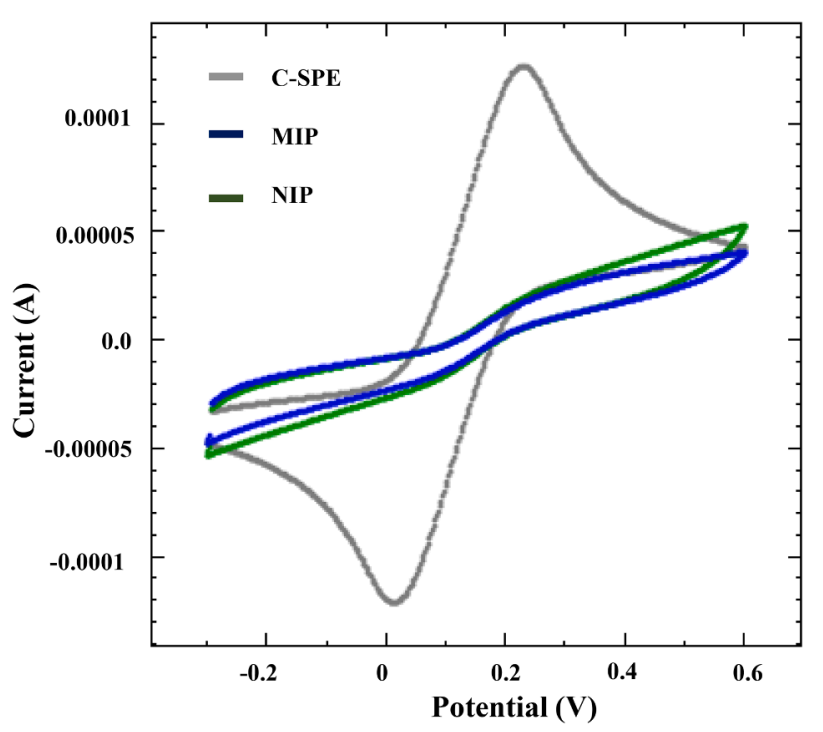

Fig. 2. (A) Electrochemical synthesis of MIP. Records obtained with $5.0 \times$ $10^{-3} \mathrm{M} \mathrm{K}_{3}\left[\mathrm{Fe}(\mathrm{CN})_{6}\right]$ and $5.0 \times 10^{-3} \mathrm{M} \mathrm{K}_{4}\left[\mathrm{Fe}(\mathrm{CN})_{6}\right]$ in $\mathrm{KCl}$ electrolyte, carried out by CV assays for MIPs/NIPs. 
the oxidation/reduction peaks almost disappeared, showing that the surface was "blocked" due to the formation of the polymeric layer. In addition, through the Nyquist plot (Fig. S2) that consisted of a semicircle, it was possible to observe that before electropolymerization the resistance to charge transfer $\left(\mathrm{R}_{\mathrm{ct}}\right)$ was lower than that obtained after the polymer changes. Thus, the polymer formed on the surface of C-SPE significantly increased the $\mathrm{R}_{\mathrm{ct}}$ due to the non-conductive properties of poly(2-aminophenol).

With regard to the MIP, the $R_{c t}$ increased significantly after electropolymerization, since the protein was inside the polymeric network and its presence in the matrix alters the electrical properties of the surface where the polymer is being formed. Regarding the NIP, it was synthetized without the protein and it was found that the resistance obtained was higher than that obtained for the MIP. This can be justified by means of two events. First, the presence of the protein hindered the polymerization and therefore the NIP layer was thicker/denser than the MIP, thereby evidencing a higher resistance value. Second, the isoelectric point of Gal-3 $(\approx 8.58)$ is higher than the pH of the buffer $(\approx 7.4)$, menaing that it was protonated predominantly with a positive charge, increasing the possibility of the sensing film to attract the negativelycharged standard iron solution.

\subsection{Protein removal}

To remove the protein that was imprinted molecularly on the surface of the polymer, it was necessary to expose the C-SPE's to an oxalic acid solution, which would break the peptide bonds between the protein's amino acids. The selection of protein removal agent is, however, important since the goal is only to remove the protein without interfering with the struture of the polymer. Oxalic acid was found here a suitable material. Thus, after electropolymerization of MIP and NIP, $5 \mu 1$ of $0.5 \mathrm{M}$ oxalic acid solution was placed on the surface of the working electrode of each C-SPE and incubated at room temperature overnight. After the incubation, the electrodes were washed with $\mathrm{KCl}$ and conditioned in PBS, for approximately $30 \mathrm{~min}$ to stabilize the $\mathrm{pH}$.

With the removal of the protein, changes in $R_{c t}$ occurred. It was found a decrease in the $\mathrm{Rc}_{\mathrm{t}}$, both in NIP and MIP sensing films, however this was more significant in MIP.

It would be expected that in the NIP there would be no changes after the action of the oxalic acid, since it is synthetized without the protein. However, this slight decrease in $\mathrm{R}_{\mathrm{ct}}$ value may be related to the partial loss of the polymer, which may have been partially digested by the acid and/or to an altered protonation of the polymer.

The MIP suffered a significant decrease in the $\mathrm{R}_{\mathrm{ct}}$ values, as expected. The acidic degradation of the proteins yielded the formation of cavities in the polymer, which would facilitate the access of the redox probe to the electrode surface, thereby promoting a decrease in the resistance to charge transfer.

\subsection{Qualitative analysis of materials}

Qualitative analyses were performed directly on the C-SPE's at different stages of the assembly of the sensor surface and was performed by Raman Spectroscopy. The Raman spectra of the working electrodes MIP and NIP are shown in Fig. 3. As known, G-band (associated with the vibration bond stretching of all pairs of $\mathrm{sp}^{2}$ atoms in rings and chains) and D-band (related with hexagonal lattice defects of carbon-based materials and disordered in $\mathrm{sp}^{3}$-carbon structure) are the most significant peaks. The ratio of the Raman intensity of these peaks, stated herein as $I_{G} / I_{D}$, reflects the material organization, from which a ratio increase is linked to an increasing disorder degree within the materials.

According to the results, the C-SPE without any modification $\left(\mathrm{I}_{\mathrm{G}} / \mathrm{I}_{\mathrm{D}}\right.$ $=1.61$ ) showed higher ratio in relation to the other sensor stages, which can be justified by the crystalline structure of the electrode surface. Regarding MIP before protein removal $\left(\mathrm{I}_{\mathrm{G}} / \mathrm{I}_{\mathrm{D}}=1.14\right)$ this has a higher value than MIP after removal $\left(\mathrm{I}_{\mathrm{G}} / \mathrm{I}_{\mathrm{D}}=1.08\right)$ which may be associated

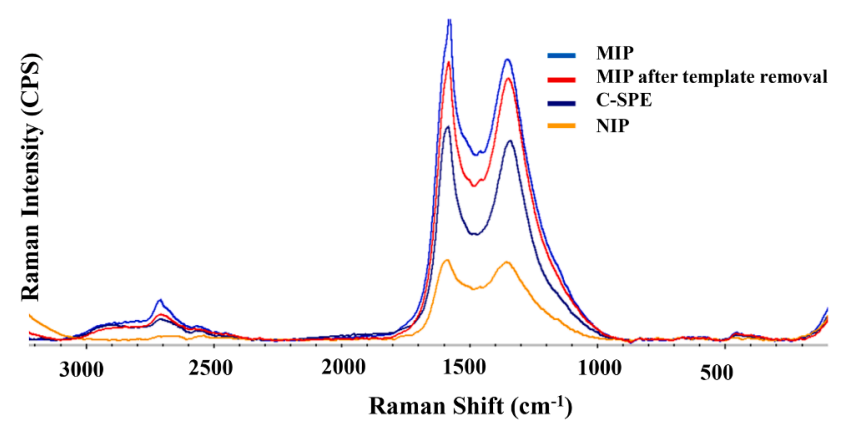

Fig. 3. . RAMAN spectra of the nanomaterials.

with the introduction of structural defects on the surface. Regarding the MIP after removal $\left(\mathrm{I}_{\mathrm{G}} / \mathrm{I}_{\mathrm{D}}=1.08\right)$ and considering that $\mathrm{NIP}\left(\mathrm{I}_{\mathrm{G}} / \mathrm{I}_{\mathrm{D}}=1.09\right)$ was also subjected to an acid treatment, it was found that the values obtained are very similar, what was expected since the polymeric matrix was the same.

\subsection{Analytical performance of the sensor}

To evaluate the analytical performance of the biosensor, it was necessary to create a calibration curve which expresses the relationship between the measured signal and the concentration of the analyte, allowing the analysis of the sensor's ability to interact again with the protein in the cavities formed after its removal. This process consisted of adding $5 \mu$ l of standard protein concentrations to the working electrode, and incubating it in a desiccator, for about $20 \mathrm{~min}$. After the incubation of each concentration, the electrode surface was washed with $\mathrm{KCl}$ and the electrochemical measurement was done with the standard iron redox solution, to observe the behaviour of the sensor at various protein concentrations ( $5 \mathrm{ng} / \mathrm{mL}-50 \mu \mathrm{g} / \mathrm{mL}$ ).

Regarding the $\mathrm{R}_{\mathrm{ct}}$ values obtained, both NIP and MIP showed a decreasing trend in resistance with the increase in protein concentration, which confirmed the existence of protein binding to the sensor surface (Fig. 4 left). This is consisten with the fact that a positively charged species is binding to the sensing film. The calibration curve was obtained from the graph resulting from the $\mathrm{R}_{\mathrm{ct}}$ values of the Nyquist Plot diagram against $\log$ (concentration). The slope of the observed linear trend (Fig. 4 right) represented the sensitivity of the sensing system.

Under optimized conditions, the MIP displayed a dynamic response range between $5.0 \mathrm{ng} / \mathrm{mL}$ and $50 \mu \mathrm{g} / \mathrm{mL}$. When compared to the MIP sensor, the NIP did not demonstrated a linear response to Gal-3 in all range of concentrations analyzed, suggesting that the main binding mechanism was related with the presence of the imprinted Gal-3 cavities (positions acting as plastic antibody) within the polymeric matrix.

\subsection{Serum analysis}

Furthermore, in order to assess the behavior of the biosensor in a more realistic context, tests were carried out with the preparation of standard solutions of Gal-3 in human serum (Cormay Serum HN), in a range of concentrations between $0.5 \mathrm{ng} / \mathrm{mL}$ and $5.0 \mu \mathrm{g} / \mathrm{mL}$. This commercial serum is a very complex matrix with the capability to produce valuable data concerning the selectivity of the biosensor under conditions of real sample analysis.

Fig. S3 shows the results obtained from the calibration after the incubation during $20 \mathrm{~min}$ with different concentrations of Gal-3. It showed that the MIP presented improved results to those obtained with the use of standard solutions prepared in PBS. The MIP sensor presented a lower limit of linear range that was 10 times lower, when compared with the calibration curve in PBS buffer (Fig. 4), which demonstrated its ability to measure lower concentrations in a more real context. Under optimized conditions, the MIP displayed a dynamic response ranging between 0.5 

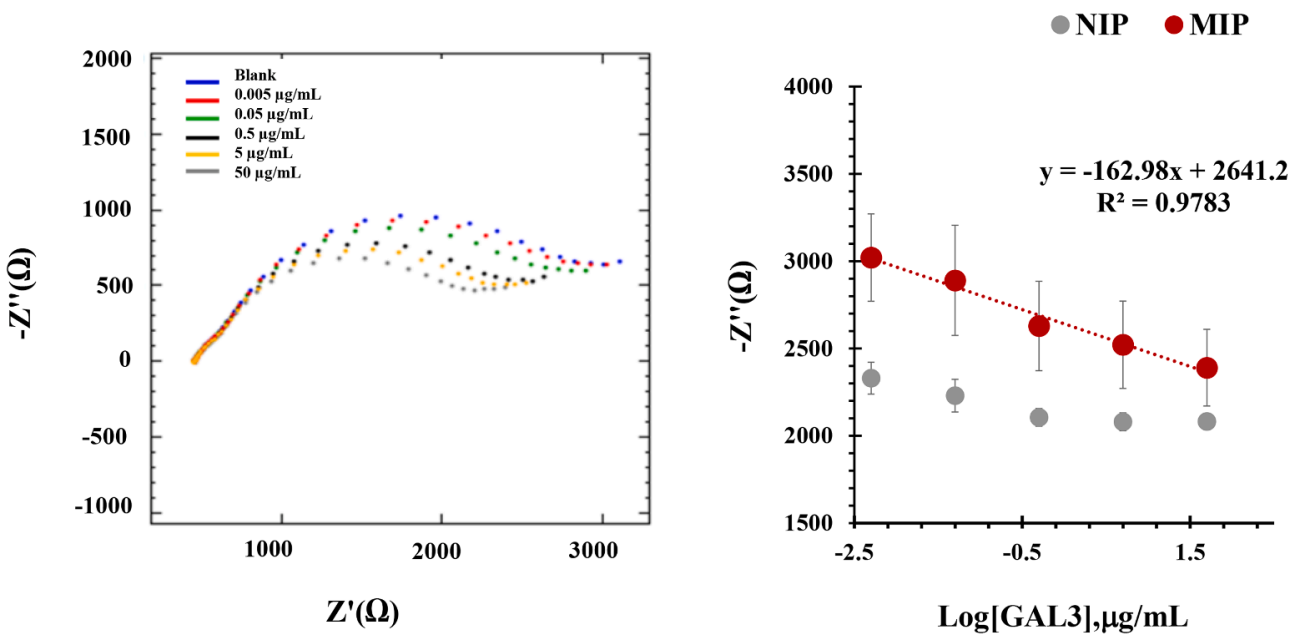

Fig. 4. (A) EIS measurement of MIPs in $5.0 \times 10^{-3} \mathrm{M} \mathrm{K}_{3}\left[\mathrm{Fe}(\mathrm{CN})_{6}\right]$ and $5.0 \times 10^{-3} \mathrm{M} \mathrm{K}_{4}\left[\mathrm{Fe}(\mathrm{CN})_{6}\right]$ in $\mathrm{KCl}$ electrolyte with different concentrations of Gal-3 in PBS. (B) The corresponding calibration curves of NIP and MIP.

$\mathrm{ng} / \mathrm{mL}$ and $5.0 \mu \mathrm{g} / \mathrm{mL}$.

Overall, these results appeared promising for direct applications in the PoC context as within the concentration range studied the response of the MIP was controlled by the interaction of Gal-3 with the rebinding sites, with insignificant nonspecific response detected.

\subsection{Selectivity}

To evaluate the selectivity of the sensor and verify its ability to detect a specific analyte in a sample containing other compounds, in this case, glucose, creatinine, BSA and CA $15-3$, the sensor was incubated in separate solutions of interfering species. For this, the incubation period of the C-SPE's with the interfering species was $20 \mathrm{~min}$ to ensure that equilibrium was reached, even in the presence of these compounds. After analyzing the results (Fig. S4) it was found that the binding of glucose $(0.1 \%)$ and CA15-3 protein (1.5\%) was insignificant. Regarding creatinine and BSA, these showed higher values of interference, $3.2 \%$ and $2.6 \%$, respectively. However, these values may be neglected since the range of linearity of the sensor calibration in serum is between 0.5 $\mathrm{ng} / \mathrm{mL}$ and $500 \mu \mathrm{g} / \mathrm{mL}$ and the physiological value of Gal-3 is $30 \mathrm{ng} / \mathrm{mL}$. In this way, the sample can be diluted about 60 times, reducing the interference of these compounds in the analytical signal.

\section{Conclusion}

As previously mentioned, melanoma is a disease of increasing incidence and has become a public health problem. Thus, there is the need to create new strategies to combat mortality and improve the quality of life that is associated with this type of disease. Thus, in order to create a new strategy for monitoring radiotherapy during the melanoma treatment process, an electrochemical biosensor was developed for the detection of Gal-3, which is associated with a worst prognosis of the disease. In general, the biosensor developed herein has shown good results in terms of selectivity, detection limit (in order of $\mathrm{ng} / \mathrm{mL}$ ), response time (maximum incubation time of $20 \mathrm{~min}$ ) and reproducibility. Regarding the response limits, it was found that these were in the range of $0.50 \mathrm{ng} / \mathrm{mL}$ and $5.0 \mu \mathrm{g} / \mathrm{mL}$, which included the physiological values of the protein $(30 \mathrm{ng} / \mathrm{mL})$. Thus, the development of this biosensor using plastic antibodies has proven to be simple and sensitive, makes the development of new Gal-3 sensors promising.

Finally, and as mentioned, Gal-3 is a protein that can be used in conjunction with other clinical biomarkers in different pathologies. In the scenario where the biosensor for Gal-3 was ready to be used in a real context, it would still be interesting to evaluate its diagnostic value as a
Alzheimer marker.

In short, an easily produced, inexpensive, fast and sensitive biosensor for Gal-3, which perfectly covers physiological limits, could have numerous biomedical applications and potential clinical impact not only oncology that could and should be explored.

\section{Declaration of Competing Interest}

The authors declare that they have no known competing financial interests or personal relationships that could have appeared to influence the work reported in this paper.

\section{Acknowledgements}

MindGAP -, Bridging the gap between Mind, Brain and Body: exosome role and monitoring, FET-Open/H2020, European Commission (Brussels), Grant agreement 829040.

0624_2IQBIONEURO_6_E, , Impulso de una red de I + i en química biológica para diagnóstico y tratamiento de enfermedades neurológicas EP - INTERREG V A España Portugal (POCTEP).

\section{Appendix A. Supplementary data}

Supplementary data to this article can be found online at https://doi. org/10.1016/j.microc.2021.105992.

\section{References}

[1] A.H. Shain, B.C. Bastian, From melanocytes to melanomas, Nat. Rev. Cancer 16 (2016) 345-358.

[2] A.H. Shain, B.C. Bastian, From melanocytes to melanomas (vol 16, pg 345, 2016), Nat. Rev. Cancer 20 (2020) (2016) 355, 355.

[3] R.L. Mort, I.J. Jackson, E.E. Patton, The melanocyte lineage in development and disease, Development 142 (2015) 620-632.

[4] M. Cichorek, M. Wachulska, A. Stasiewicz, A. Tyminska, Skin melanocytes: biology and development, Post. Dermatol. Alerg. 30 (2013) 30-41.

[5] OECD/EU, in: Health at a Glance: Europe 2018: State of Health in the EU Cycle, OECD Publishing, Paris, 2018, https://doi.org/10.1787/health_glance_eur-2018en.

[6] J.S. Ankeny, B. Labadie, J. Luke, E. Hsueh, J. Messina, J.S. Zager, Review of diagnostic, prognostic, and predictive biomarkers in melanoma, Clin. Exp. Metastasis 35 (2018) 487-493.

[7] A. Cherobin, E.M.A. Goulart, A.J. Wainstein, B. Gontijo, F.V. Bittencourt, Prognostic factors for metastasis in cutaneous melanoma, J. Deutschen Dermatologischen Gesellschaft 11 (2013) 73-74.

[8] A. Cherobin, A.J.A. Wainstein, E.A. Colosimo, E.M.A. Goulart, F.V. Bittencourt, Prognostic factors for metastasis in cutaneous melanoma, Anais Brasil. Dermatol. 93 (2018) 19-26. 
[9] L. Kretschmer, K.P. Preusser, C. Neumann, Locoregional cutaneous metastasis in patients with therapeutic lymph node dissection for malignant melanoma: risk factors and prognostic impact, Melanoma Res. 12 (2002) 499-504.

[10] S.Y. Lim, J.H. Lee, R.J. Diefenbach, R.F. Kefford, H. Rizos, Liquid biomarkers in melanoma: detection and discovery, Molecular Cancer 17 (2018).

[11] P. Karagiannis, M. Fittall, S.N. Karagiannis, Evaluating biomarkers in melanoma, Front. Oncol. 4 (2015).

[12] A. Tarhini, R.R. Kudchadkar, Predictive and on-treatment monitoring biomarkers in advanced melanoma: moving toward personalized medicine, Cancer Treat. Rev. 71 (2018) 8-18.

[13] G. de Couto, M. Ouzounian, P.P. Liu, Early detection of myocardial dysfunction and heart failure, Nat. Rev. Cardiol. 7 (2010) 334-344.

[14] B.V. Hisrich, R.B. Young, A.M. Sansone, Z. Bowens, L.J. Green, B.A. Lessey, A. $\mathrm{V}$. Blenda, Role of human galectins in inflammation and cancers associated with endometriosis, Biomolecules 10 (2020).

[15] Y.T. Liu, H. Meng, S.X. Xu, X.S. Qi, Galectins for diagnosis and prognostic assessment of human diseases: an overview of meta-analyses, Med. Sci. Monit. 26 (2020).

[16] T.B. Yu, S. Dodd, L.G. Yu, S. Subramanian, Serum galectins as potential biomarkers of inflammatory bowel diseases, PLoS One 15 (2020).

[17] E.R. Brown, T. Doig, N. Anderson, T. Brenn, V. Doherty, Y. Xu, J.M.S. Bartlett, J. F. Smyth, D.W. Melton, Association of galectin-3 expression with melanoma progression and prognosis, Eur. J. Cancer 48 (2012) 865-874.

[18] I. Iurisci, N. Tinari, C. Natoli, D. Angelucci, E. Cianchetti, S. Iacobelli, Concentrations of galectin-3 in the sera of normal controls and cancer patients, Clin. Cancer Res. 6 (2000) 1389-1393.

[19] A. Boza-Serrano, R. Ruiz, S. Jimenez, V. Navarro, R. Varo, J.G. Revilla, J. Venero, J. Vitorica, A. Gutierrez, T. Deierborg, Galectin-3, a novel endogenous TREM2 ligand, detrimentally regulates inflammatory response in Alzheimer's disease, J. Cereb. Blood Flow Metab. 39 (2019) 636-637.

[20] I. Srejovic, D. Selakovic, N. Jovicic, V. Jakovljevic, M.L. Lukic, G. Rosic, Galectin-3: roles in neurodevelopment, neuroinflammation, and behavior, Biomolecules 10 (2020).

[21] N.S. Ferreira, M.G.F. Sales, Disposable immunosensor using a simple method for oriented antibody immobilization for label-free real-time detection of an oxidative stress biomarker implicated in cancer diseases, Biosens. Bioelectron. 53 (2014) 193-199.

[22] F.T.C. Moreira, S. Sharma, R.A.F. Dutra, J.P.C. Noronha, A.E.G. Cass, M.G.F. Sales, Protein-responsive polymers for point-of-care detection of cardiac biomarker, Sens. Actuators B: Chem. 196 (2014) 123-132.

[23] M. Rebelo, C. Santos, J. Costa-Rodrigues, M.H. Fernandes, J.P. Noronha, M.G. F. Sales, Novel prostate specific antigen plastic antibody designed with charged binding sites for an improved protein binding and its application in a biosensor of potentiometric transduction, Electrochim. Acta 132 (2014) 142-150.

[24] L. Truta, M.G.F. Sales, Sol-gel chemistry in biosensing devices of electrical transduction: application to CEA cancer biomarker, Curr. Top. Med. Chem. 15 (2015) 256-261.

[25] X. Wang, M. Zhao, D.D. Nolte, T.L. Ratliff, Prostate specific antigen detection in patient sera by fluorescence-free BioCD protein array, Biosens. Bioelectron. 26 (2011).

[26] R. Peltomaa, B. Glahn-Martinez, E. Benito-Pena, M.C. Moreno-Bondi, Optical biosensors for label-free detection of small molecules, Sensors 18 (2018).

[27] Y.P. Chiu, Y.C. Sun, D.C. Qiu, Y.H. Lin, Y.Q. Chen, J.C. Kuo, J.R. Huang, Liquidliquid phase separation and extracellular multivalent interactions in the tale of galectin-3, Nat. Commun. 11 (2020).

[28] B.D. Malhotra, S. Kumar, C.M. Pandey, Nanomaterials based biosensors for cancer biomarker detection. India-Japan Expert Group Meeting on Biomolecular Electronics and Organic Nanotechnology for Environment Preservation (IJEGMBE), Kyushu Inst Technol, Fukuoka, JAPAN, 2015.

[29] B.Z. Wang, U. Akiba, J. Anzai, Recent progress in nanomaterial-based electrochemical biosensors for cancer biomarkers: a review, Molecules 22 (2017).

[30] M.A. Morales, J.M. Halpern, Guide to selecting a biorecognition element for biosensors, Bioconjug. Chem. 29 (2018) 3231-3239.

[31] P.B. Luppa, L.J. Sokoll, D.W. Chan, Immunosensors - principles and applications to clinical chemistry, Clin. Chim. Acta 314 (2001) 1-26.

[32] C. Gonzalez-Solino, M. Di Lorenzo, Enzymatic fuel cells: towards self-powered implantable and wearable diagnostics, Biosensors-Basel 8 (2018).

[33] D.W. Hwang, S. Lee, M. Seo, T.D. Chung, Recent advances in electrochemical nonenzymatic glucose sensors - a review, Anal. Chim. Acta 1033 (2018) 1-34.

[34] M. Tada, Y. Iwasawa, Design of molecular-imprinting metal-complex catalysts, J. Mol. Catal. A-Chem. 199 (2003) 115-137.

[35] B. Sellergren, Molecular imprinting by noncovalent interactions enantioselectivity and binding-capacity of polymers prepared under conditions favoring the formation of template complexes, Macromol. Chem. Phys. 190 (1989) 2703-2711.

[36] D. Kriz, O. Ramstrom, K. Mosbach, Molecular imprinting - new possibilities for sensor technology, Anal. Chem. 69 (1997) A345-A349.

[37] S. Dai, M.C. Burleigh, Y.H. Ju, S.D. Waezsada, Z.L. Xue, C.E. Barnes, Molecular imprinting on sol-gel materials, Abs. Pap. Am. Chem. Soc. 218 (1999). U1064-U1064.

[38] H.Q. Shi, W.B. Tsai, M.D. Garrison, S. Ferrari, B.D. Ratner, Template-imprinted nanostructured surfaces for protein recognition, Nature 398 (1999) 593-597.

[39] A. Qureshi, Y. Gurbuz, S. Kallempudi, J.H. Niazi, Label-free RNA aptamer-based capacitive biosensor for the detection of C-reactive protein, Phy. Chem. Chem. Phys. 12 (2010) 9176-9182.

[40] C. Beltrami, A. Clayton, A.O. Phillips, D.J. Fraser, T. Bowen, Analysis of urinary microRNAs in chronic kidney disease, Biochem. Soc. Trans. 40 (2012) 875-879.

[41] C. Carrasquilla, P.S. Lau, Y. Li, J.D. Brennan, Stabilizing structure-switching signaling RNA aptamers by entrapment in sol-gel derived materials for solid-phase assays, J. Am. Chem. Soc. 134 (2012) 10998-11005.

[42] R. Jiang, K. Wang, Q. Wang, Y. Xing, X. Yang, New Nucleic Acid Aptamer or Its Derivative Useful for Detecting Myoglobin and Preparing a Myoglobin Detecting Kit, Univ Hunan.

[43] N. Rupcich, R. Nutiu, J.D. Brennan, Y. Li, Immobilizing Nucleic Acid aptamers for Multianalyte Biosensing, Metabolite Profiling, by Combining at Least One Nucleic Acid Aptamer with a Sol-gel Precursor and Treating the Aptamer and Precursor for a Gel to Form, Univ Mcmaster.

[44] K. Ikebukuro, K. Tsukakoshi, K. Sode, K. Ikefukuro, New Aptamer having G Quartet Structure and Capable of Binding to Amyloid Protein Oligomer, Univ Tokyo Agric\&Technology.

[45] S.D. Jayasena, Aptamers: an emerging class of molecules that rival antibodies in diagnostics, Clin. Chem. 45 (1999) 1628-1650.

[46] J.R. Collett, E.J. Cho, A.D. Ellington, Production and processing of aptamer microarrays, Methods 37 (2005) 4-15.

[47] B. Strehlitz, N. Nikolaus, R. Stoltenburg, Protein detection with aptamer biosensors, Sensors 8 (2008) 4296-4307.

[48] Z.Y. Tang, J.L. He, J. Chen, Y.Z. Niu, Y.L. Zhao, Y.C. Zhang, C. Yu, A sensitive sandwich-type immunosensor for the detection of galectin-3 based on N-GNRs-FeMOFs@AuNPs nanocomposites and a novel AuPt-methylene blue nanorod, Biosens. Bioelectron. 101 (2018) 253-259.

[49] M.L. Yola, N. Atar, Amperometric galectin-3 immunosensor-based gold nanoparticle-functionalized graphitic carbon nitride nanosheets and core-shell TiMOF@COFs composites, Nanoscale 12 (2020) 19824-19832.

[50] B.R. Arnold, A.C. Euler, A.L. Jenkins, O.M. Uy, G.M. Murray, Progress in the development of molecularly imprinted polymer sensors, Johns Hopkins Appl. Tech. Dig. 20 (1999) 190-198.

[51] S. Kadirsoy, N. Atar, M.L. Yola, Molecularly imprinted QCM sensor based on delaminated MXene for chlorpyrifos detection and QCM sensor validation, New J. Chem. 44 (2020) 6524-6532.

[52] C.P. Boke, O. Karaman, H. Medetalibeyoglu, C. Karaman, N. Atar, M.L. Yola, A new approach for electrochemical detection of organochlorine compound lindane: development of molecular imprinting polymer with polyoxometalate/carbon nitride nanotubes composite and validation, Microchem. J. 157 (2020).

[53] M.L. Yola, N. Atar, Development of molecular imprinted sensor including graphitic carbon nitride/ $\mathrm{N}$-doped carbon dots composite for novel recognition of epinephrine, Composites Part B: Eng. 175 (2019).

[54] M. Beytur, F. Kardas, O. Akyildirim, A. Ozkan, B. Bankoglu, H. Yuksek, M.L. Yola, N. Atar, A highly selective and sensitive voltammetric sensor with molecularly imprinted polymer based silver@gold nanoparticles/ionic liquid modified glassy carbon electrode for determination of ceftizoxime, J. Mol. Liq. 251 (2018) $212-217$.

[55] N. Ozcan, H. Medetalibeyoglu, O. Akyildirim, N. Atar, M.L. Yola, Electrochemical detection of amyloid-beta protein by delaminated titanium carbide MXene/multiwalled carbon nanotubes composite with molecularly imprinted polymer, Mater. Today Commun. 23 (2020).

[56] P.S. Sharma, A. Pietrzyk-Le, F. D'Souza, W. Kutner, Electrochemically synthesized polymers in molecular imprinting for chemical sensing, Anal. Bioanal. Chem. 402 (2012) 3177-3204.

[57] R.S. Gomes, F.T.C. Moreira, R. Fernandes, M.G.F. Sales, Sensing CA 15-3 in pointof-care by electropolymerizing O-phenylenediamine (OPDA) on Au-screen printed electrodes, PLoS One 13 (2018).

[58] F.T.C. Moreira, B.A.G. Rodriguez, R.A.F. Dutra, M.G.F. Sales, Redox probe-free readings of a beta-amyloid-42 plastic antibody sensory material assembled on copper@carbon nanotubes, Sens. Actuators B: Chem. 264 (2018) 1-9.

[59] M.S.R. Khan, F.T.C. Moreira, J. Riu, M.G.F. Sales, Plastic antibody for the electrochemical detection of bacterial surface proteins, Sens. Actuators B: Chem. 233 (2016) 697-704. 